\title{
EDITORIAL
}

\section{Leadership: What's all the fuss about (and what does all the hype really deliver)?}

Attaining a leadership role in anything - be it in the local sports club through to being the leader of a country, is generally viewed as an achievement and even as aspirational. Taking on or being offered a leadership role is generally associated with recognition of ability and with enhanced social status (and, if in a paid role, often with increased financial rewards). Within the world of work, upward progression into a supervisory and then into managerial positions is equated with assuming greater and greater leadership roles.

Leadership positions may indeed be an aspiration of many but, as far as day-to-day work goes, many of us are happy to ask nothing more than having a have good manager. Good leadership is also something many of us aspire to experience - but sadly, also something we often have very little personal experience of in our own working lives.

This gap or disconnect between theory and the reality of working life seems very odd given the vast resources given over to the field. For instance, most management schools not only teach leadership at the individual course level but also develop whole programs around it. Most also offer inspiring tales of their graduates who have gone on to key leadership roles.

While leadership is very much a 'bread and butter' issue for the education sector a critical question seems to be 'where is the synthesis between the efforts of the academic world and what is being put into practice?'

The eight papers we present in this first issue of Journal of Management and Organization (JMO) for 2018 take a variety of perspectives to offer insight into some answers to this question.

We begin with Mieke Audenaert and Adelien Decramers' investigation of the circumstances under which empowering leadership fosters creative performance from employees. Their study focused on a three-way interaction of empowering leadership, problem-solving demands and creative personality. While the results appear deceptively simple (with less creative employees in jobs requiring high problem-solving demands particularly benefiting from an empowering leadership style), the paper provides for practitioner insight in the way it identifies the nuanced interplay between the contextual factors of the organization and how these interact with the personal factors of both leader and follower.

Our second paper provides another perspective to the examination of creativity to examine how leadership creates organizational value. In their paper Eldad Kollenscher, Micha Popper and Boaz Ronen deconstruct the main approaches to leadership to reveal how the traditional dichotomy of a macro-micropolarization of major leadership theories has overlooked important meso perspective processes. The authors suggest that attention to issues such as structuring will allow leaders to produce greater and more sustained organizational outcomes. The integrative theoretical framework they provide offers a unified model of corporate leadership crying out for some avid reader to pick up and test!

The practical implications of testing theory in real-world settings is a task taken up with some passion in the next few papers published in this issue. Our third contribution is 'When leadership elicits voice' by authors Chang-Wook Jeung and Hea Jun Yoon and this paper examines the influence of humble and empowering leader behaviors on the prosocial voice of subordinates. Drawing on the views of over 300 employees of a Korean business conglomerate, the results find that both humble and empowering leadership positively influence the prosocial voice of subordinates. The role of psychological empowerment also emerges as an important moderating variable - a result that ties on well with Audenaert and Decramers' paper on empowering leadership fostering employee creativity. 
While Jeung and Yoon looked at voice, our fourth paper provides a counterpoint and looks at silence. Here Jinyun Duan, Chanzi Bao, Caiyun Huang and Chad Thomas Brinsfield examine the relationship between authoritarian leadership and employee silence behavior. This study also draws on over 300 employees but moves us to the context of 16 state-owned manufacturing enterprises in China. The authors apply theories of motivation and person-environment fit to explain the mediating roles of psychological safety and organization-based self-esteem, and the moderating effects of power distance orientation. While no one will probably be surprised that the results showed that authoritarian leadership had a positive relationship with employee silence behavior, the authors take their analysis a step further. Mediation analyses revealed that psychological safety and organization-based self-esteem both partially mediate the relationship between authoritarian leadership and employee silence. They also use moderation analysis and this provides further insight with a direct relationship between authoritarian leadership and employee silence behavior being stronger for employees with high (as opposed to low) power distance orientation.

A key theme of the papers in this issue of $J M O$ is that they all devote a considerable amount of their discussion section to the implications for theory and practice are discussed. Our fifth paper is one that brings many of the separate factors and issues noted in the prior papers together. Here Ceren Aydogmus, Selin Metin Camgoz, Azize Ergeneli and Ozge Tayfur Ekmekci present two separate studies to examine the moderating effects of personality traits and the mediating effect of psychological empowerment on the relationship between perceived transformational leadership and job satisfaction. Taking the view of the followers, the first study questions whether personality traits moderate the effects of perceived transformational leadership on followers' job satisfaction. The results find that the more conscientious the employee, the stronger the relationship between perceived transformational leadership and job satisfaction. The second study replaces personality traits with the notion of psychological empowerment and finds that this also mediates the effects of perceived transformational leadership on followers' job satisfaction. At a practical level, this means that when employees perceive their leader as transformational they feel more psychologically empowered and this in turn increases their job satisfaction levels.

The importance of transformational leadership is taken a step further in our sixth paper for this edition of $J M O$ were Mozhdeh Mokhber, Wan Khairuzzaman and Amin Vakilbashi investigate the effect of transformational leadership on organizational innovation. They offer a new framework to identify the moderating effect of organization support for idea generating, risk taking and decisionmaking on the relationship between transformational leadership and organizational innovation. The results suggest that transformational leaders might not only promote innovative activity within the organization but also play an important role in ensuring the market success of the innovations.

The results from the studies noted to date make a big call on the role of leadership in organizational success and prompts us to return once again to the suggestion in our first paper by Audenaert and Decramer and the importance of organizational context. Our seventh paper takes up this theme as Amber Yun-Ping Lee, I-Heng Chen, Po-Chien Chang examine the notion of the sense of calling with its' connection to the meaningfulness of work. They find that while a sense of calling was positively related to individual performance, a supportive organizational climate also plays an important role in the relationship between sense of calling and contextual performance. This result further reinforces the view that factors must be considered at both the organizational and individual level. Placing this back within the leadership theme which dominates this issue of $J M O$, the notion of leadership is as much about the organization a leaders operates in as well as the followers of the leader as it is about the individual leader.

This is borne out in the final paper where the universality of transformational leadership is questioned by Ann-Louise Holten, Anne Bøllingtoft, Isabella Gomes Carneiro and Vilhelm Borg. Their investigation looked at transformational leadership with respect to employee perceptions and three 
outcomes: job satisfaction, self-rated health and well-being among employees of different national and cultural backgrounds, yet within a shared national and sectorial setting. Drawing on just under 3,000 employees in a repeated measures study, the authors found that transformational leadership was not a universal predictor of outcomes as it failed to predict change in the outcomes for immigrants. The study has important implications and suggests the need for organizations to apply a hybrid of universalistic and contingency paradigms when leading composite employee groups.

This editorial began with perhaps a rather cynical view as to the value of leadership education. From a general perspective, attaining leadership roles is often conflated with managerial progression and the notion of hierarchy. From an academic view, much of the research we do revolves around the notion of moderating and mediating variables. This has indeed been a key part of the investigative strategy of many of the papers and it is often the point at which many practitioners become confused with such seemingly pointless technicalities and lose interest. As many undergraduate students are told, a simple way to sum them up is that a moderator variable influences the strength of a relationship between two other variables while a mediator explains the relationship between the two other variables.

However, as each of the eight papers presented here has shown, the role and need for leadership is indeed deeply embedded within organizational operation and practice. The question in fact is very much more about how and why it operates. I hope that these papers therefore make some contribution to further developing and understanding of the nuances of leadership - particularly in terms of where there are relationships (or often just as important, where there are not), as well as where there are, just how strong and important these relationships are. Yes, there is hype but there is evidence as well as also great promise of delivering on the rhetoric. While good leadership may not yet surround us in our own organizations, we can hope that ongoing research may create a world (and here can I offer the hope that this is not just that of work?), where it becomes the norm.

Tui McKeown

Associate Professor, Editor in Chief Monash Business School, Monash University, Melbourne, Australia 